\title{
Community Development Programs For Socio-Economic Development In Pakistan
}

\author{
Siraj Bashir \\ Department of Social Work \\ University of Karachi \\ Nasreen Aslam Shah \\ Social Work \& Women's Studies \\ University of Karachi
}

\begin{abstract}
Community development program is defined as the set of programs and policies designed to improve the socio-economic condition and also use the existing resources in better way. It is an organized process where member's efforts of a community can be joined with the collaboration of government departments and non-governmental organizations to improve and evolve community socially, economically and culturally. In Pakistan, the first community development program was introduced in 1951 with the establishment of pilot project in Karachi, by the federal government. Since 1951 till today various community development programs have been implemented by government and non-government organizations (NGOs) to improve the living standard of people. The purpose of the study was to evaluate the impact and contribution of community development programs for socio-economic development in Pakistan. The research study endeavored to analyze the social and economical impacts of these programs on the communities where the programs were implemented. The study included interviews with government officials, NGOs staff and beneficiaries in the field. The findings of study shows that programs in general have positive impacts and appreciated but a lot of work are needed to be done for the welfare of whole society. The recommendations were made as to the best practices of community development programs for policy makers and NGOs to improve the living standard of people in the country.
\end{abstract}

Keywords: Community Development Programs, Socio-Economic Development, Pakistan.

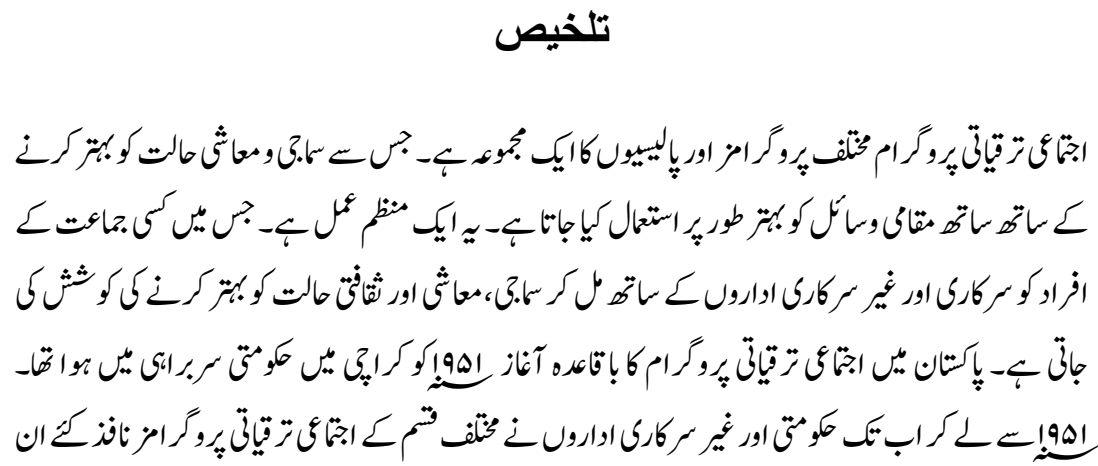




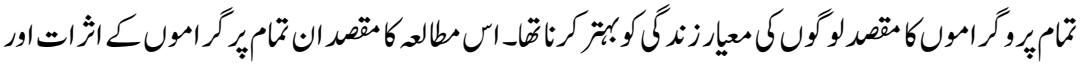

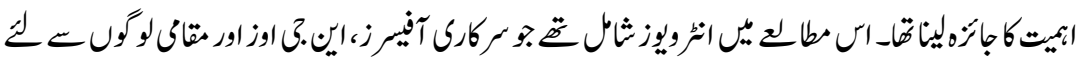

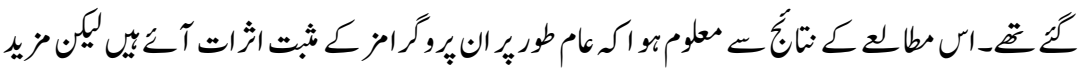

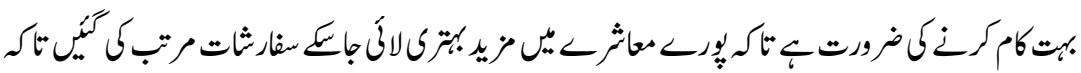

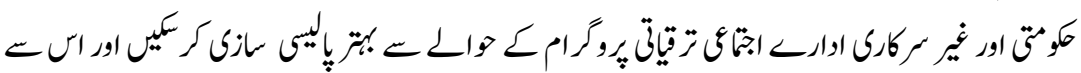

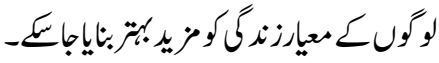

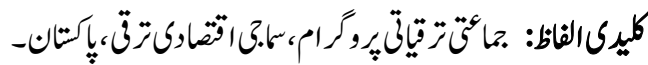

\section{Introduction}

Community development is an approach to bring about changes in whole community. These changes are actually planned at development of the community. It involves all people, particularly of the areas in the development activities. Community development can provide opportunities to local people to improve the socio-economic condition and also use the existing resources in better way. Community development is defined as " a participatory peoplecentered process that involves bring together, mobilizing or organizing people, keeping them together and enabling them to work together to address their need and issues and thus to facilitate their own, their communities' and society's comprehensive development as the social approach"(Pawar, 2014).

It stressed the process where members of the community set to make and take collective actions regarding their local issues. They recognize their local issues and felt needs and take initiatives collectively according to their available resources. They also request for external aids from government and donor agencies (UNO, 1975) The concept of community development is linked in words of community participation, community empowerment and community capacity (Rubin, H \& Rubun, 1992) and thus, community development is a movement designed to improve better living for the whole community, with the active participation of people and if possible on the initiative of the community (Mukherji, 1961).

The aims of community development program is to develop self-help confidence in the individual and cohesion in the community so that the people are able to manage their affairs by themselves and make the local communities selfgoverning units to develop and sustain strategies and mechanisms for improving access to local services. According to Ferrinho (1980), it is the social movement, which occurs when somebody, representing the importance of human development and people's felt needs, encourages the local people as a part of 
action. Likewise, Dunham (1970) says that community development is a process which facilitates the community to become aware of the factors and forces affecting their quality of life. It also tries to empower the people with the skills needed for improving their living condition. In this process, people get together, communicate and discuss their problems, prioritize their needs, plan accordingly and take actions to overcome the problems.

Community development as a voluntary participation of local community, individuals in a systematic process to bring some desirable improvements, especially health, education, housing, recreation in the targeted community. These efforts give a clear direction to strengthening community structure for human well-being. As Maimunah Ismail (2001) mentioned. Community development is a process of activities at community level that are planned and organized movements in a particular way so as to improve the standard of life the community as means of social, economy, culture and environment through initiatives and functioning participation and with minimum external help.

Pearce, J. (2000) recommended that community development approach have three main branches: collective empowerment, collective leadership and leading change through dialogue. It is need of time to use community development approach at rural areas as well as urban areas where local people should be involved in all stages such as need assessment, planning and implementing the programs. In this regard, we can say that community development process may be carrying out for various purposes:

- To improve the different sectors of community such as health, education, housing, recreation and so forth.

- To motivate community to prepare community based plans to solve their issues.

- To strengthen the capacities of local communities to identify their resources and interests

- To develop community leaders

- To build a understandable relationship and cooperation among community individuals

- To develop functioning community groups and organizations

However, community development has been considered as a method, a process and a program. It needs a number of planned interventions to achieve its purposed aims. These planned interventions may be taken for a single problem of the community or can focus on a number of issues of that community. For instead, these programs can be related to education, health, housing, nutrition, recreation, agriculture and the same. 
The development proposes that the emerging nations move through a series of phases of evolution towards modernization is on the basis of social, political and economic stabilization. Nowadays in the world, every country considers community development as an important approach for public development, therefore; every country attempts to implement several programs of community development to improve the living standard of communities. Community development concept has been adopted rapidly by a variety of donor agencies as well as by many national governments in the world. A number of modest national community development programs were implemented primarily in British Africa around 1948. The first major community development program was initiated in India in 1952 with the support from Ford Foundation and the United States Foreign Economic Assistance Agencies (Anwer, 2008).

When Pakistan attained independence in 1947, the state faced a number of social and economic problems. In the beginning, there were the problems of poor infrastructure, illiteracy, rehabilitation of refugees, lack of funds and widespread poverty of masses. To resolved these issues, the government of Pakistan sought the assistance of the United Nations with the view to formulating community development programs. Community development as an approach was introduced in 1951 when first UN advisor came in March 1951; he analyzed the problems and needs and suggested the professional approach. Since 1951, various community development programs have been implemented by government and non-governmental organizations (NGOs). The main aim of various community development programs was to bring to plan socio-economic change in the country.

\section{Socio-Economic Situation in Pakistan}

Socially, people in Pakistan are divided into various tribes with various cultural and historical backgrounds. Pakistan's people and traditions reflect a mixture of many varied cultural influences. People are living together as one society. The Urdu language is the national language. Economically, Pakistan is a developing country in Asian continent with the middle-income rate. The majority of the population is poor and live in extreme poverty. The present government of PML $(\mathrm{N})$ tries hard to raise economic growth and improve the standard of living to the people. The economic growth of the country rises very slowly and with the years the economic situation continues to be poor. The most important economic activity in Pakistan is agriculture. The majority of the population is largely dependent on agriculture for their life. It estimated that sixty-seven percent of the population is living in rural areas and most of them depend on agriculture for their lives.

According to UNO (2014), Pakistan remains a developing country in the world with per capita of 3,149 US dollars ranking 144 th in the world. The country was 
more stricken by floods, terrorism, energy crisis, food shortage, unemployment, inequality and famine in the last three decades than any other country in the world. Of the deprived population, about three out of ten people are suffering from a shortage of health facilities in hospitals, five out of ten not have access to primary education and at least four out of ten have abysmal standards of living. More than $50 \%$ of population does not have access to safe drinking water and minimum nutrition. According to World Bank (2015), Pakistan recent economic growth rates are encouraging and the economy grew by $4.4 \%$ in 2015 . Yet a number of the citizens are still living in poverty. The development of the food needs of the country does not equal the population annual growth rate of $1.6 \%$. Meanwhile, drought and war has damaged the economy and placed the country in a desperate situation.

For many decades, Pakistan has gone through a range of social, economic and political crises. Furthermore, various planned have been implemented to attempt these issues. Since 2013, the current Govt. of Pakistan Muslim League (N) has pursued some positive steps to steady the economic and basic needs and ultimately get healthy and dynamic.

\section{The Need of Community Development Programs in Pakistan}

In the present era, each country aims to implement community development programs as a result of it is thought-about an essential approach for national development, therefore for this purpose, each country tries to implement variety of community development programs to enhance the living standard of individuals in their countries.

Community development approach in Pakistan is neither a new nor it is an as shocking concept. In last three decades, it has been considered as an approach for community development. Community development approach helps communities for collective power and strength. Community development is the key to bringing improvement in a community that is intensively felt.

Thousands of individuals in Pakistan and particularly in rural communities live in underdeveloped areas. They do not have access to basic facilities within the ordinal century.

Even today babies are born by traditional and undisciplined midwives, diseases like malaria, diarrhea, and infectious disease are rampant, kids tormented by a scarcity of proper nutrition, illiteracy, and infant mortality rate are terribly high, speedy growth, majority folks living under poverty level, violence against girls and vulnerable folks then forth. 
However, all these issues need to be tackled for the human well-being in order to change this image; one has to implement a plan systematically and widely. Proper and desirable efforts should be made to reduce this situation and get minimum essential basic facilities to bring improvement in their lives. To bring a planned change, there is a need to carry community development programs at local levels. Attempts should be made to improve the socio-economic conditions of people by implementing programs on improving health facilities, providing educational facilities, developing industrial sector, improving agricultural sector, reducing infant and maternal mortality etc.

\section{Objectives of the Study}

The overall purpose of the research study was to know impacts and contribution of community development programs for social development. However, the specific objectives of the study are:

- To examine the impacts and challenges of community development programs

- To examine the role of community development programs in raising the living conditions of the people in the study area.

- To examine the level of awareness of community development programs for social development

- To examine the developing and establishing recommendations for public and private sectors regarding of implementation community development programs in systematic way.

\section{Review Literature}

\section{Community Development Programs by Government of Pakistan}

Community development as an approach officially was introduced in 1951, when first UN advisor came in March 1952, analyzed the problems and needs suggested professional approach. Since 1951 till today various community development programs were implemented by government and non-government organizations (NGOs). The main aims of various community development programs were to bring to planned socio-economic change in the country. Different federal ministries, provincial departments and autonomous bodies are responsible for implementing the community development programs in Pakistan. Since, 1951 till today the following main programs were implemented by government of Pakistan in country.

The Village Agriculture Industry Development (V-AID) was the first formal community development program in Pakistan with the financial support of the United State Agency for International Development and Ford Foundation and designed to solve the people problems especially vulnerable people though 
mobilization of the government resources with the participation of the local community. The primary purpose of Village-AID Program was to build up rural capital through improved farming practices, cottage industries and animal husbandry as well as gives the effective connection between line Departments to reduce poverty (Abbas, et al., 2009).

Integrated Rural Development Program (IRDP) was launched in 1972 basing upon the results of an experimental project for integrated rural development called Shadab Pilot Project which was proposed to integrate activities of different departments by bringing them at one main point (called Markaz) amidst a group of 50 to 60 villages. The program was designed to achieve self-sufficiency in food and to improve the socio-economic conditions of the small and medium farmers living at gross-root level, to reduce poverty and to improve the standard of life of people (Chaudhry, 2002).

The People's Program was initiated by Pakistan People's Party government in April, 1989. The purpose of the program was to improve and develop the social and physical infrastructure, mobilize the local resources, encourage the people for productive efforts and investment in human capital and to give welfare services to deprived population such as women, youth, aged and disabled (mental or physical) and to provide equal jobs opportunities for them(Qureshi,2001).

Social Action Program federal and provincial government launched multi-sectors program named 'Social Action Program' in 1993-96. The key aim of the program was to address the basic needs that were not covered by last development programs and started the Interim Poverty Reduction Strategy Paper (IPRSP) in November 2001 focusing attention on the key objective of alleviating poverty and re-developing economic growth (Aziz, 2009).

Benazir Income Support Program (BISP) was started in July 2008 by Pakistan People's party with the objective of consumption smoothening and cushioning the negative outcomes of slow economic growth, the food crisis and inflation on the poor, particularly women, through the provision of cash transfers of Rs. 1,000/month to eligible families (Shanza \& Sara, 2010).

\section{Community Development Programs Models by NGOs}

Some of countrywide and international NGOs have launched a number of community development programs in Pakistan. Among these community development programs the most vital programs have become very well-known which were applied by the following NGOs: Orangi Pilot Project, Aga Khan Rural Support Program and National Rural Support Programs. The details of the following models are under: 
The Orangi Pilot Project (OPP) is a non-public and non-political organization which was set up in 1980 to guide local groups to enhance their quality of existence in Karachi. By means of providing social and technical direction to inspire the mobilization of local management and financial assets, and the positioned into the practice of supportive act. The approach is to carry and improve community development programs and increase partnerships with the government and Organi based corporations for development primarily based on local resource. This is inspecting the troubles of the vicinity, people's proposals, the constrained get within the proposals, then through a method of motion studies and extension education evolving viable answers promoting participatory movement. In brief growing low-fee package deal of suggestion, guiding and facilitating community organizations for self-assist and business enterprise with the government (Hasan, 2010).

The Aga Khan Rural Support Program (AKRSP) is a private, non-denominational development support agency established by the Aga Khan Foundation (AKF) in 1982 to support local communities to improve their quality of life at GilgitBaltistan and Chitral. The AKRSP method is based on the principle of selfcontrolled improvement through the three pillars of social, financial and human capital development, with physical capital comprised within the approach in the mid-Nineteen Nineties. The AKRSP evolved the approach of social mobilization via which village and intra-village level institutions are established and supported via the program (AKRSP, 1999). Since Village Organizations are ruled by men, women's' Organizations (WOs) characteristic in much the same way, having a key micro-credit function, supplying a forum for dialogue and choice-making and providing a platform for sporting out diverse projects ( Khan \& Mahood,1992).

National Rural Support Program (NRSP) is a non-earnings corporation which was established on November 1991 under the section 42 of companies Ordinance 1984. The conceptual foundation and purposes came from the experiences of the Aga Khan Rural Support Program. The primary project was carried out in some villages across the capital city of Islamabad with a monetary assist of Orange Project. NRSP's order is to relieve poverty by means of connecting people's ability and start development programs in Pakistan (NRSP, 2014).

\section{Related Studies on Community Development Programs}

The term community development has been practiced to explain programs to improve socio-economic condition at the grass root level since the early nineteenth century. Community development as a profession has deep roots, it has been concern of social workers, sociologists for more than two hundred years, however, the different events such as democratic political revolutions of France and Britain and social World wars play a very essential role in the standing of 
community development (Ife, 1999). In 1948 the term community development was first used officially at the British Colonial Office's Cambridge Conference on the development of African Initiative. Community development was proposed to help the British colonies in African prepare for independence by improving local government and developing their economics (Anwer, 2008a).

During the 1950s and 1960s, social change and collective action again garnered much attention due to the need to rectify dismal conditions within povertystricken rural areas and areas of urban decline. The civil rights and antipoverty movements led to the recognition of community development as a practice and emerging profession.(Lukkarnen,2005). Newly independent nations implemented these methods in their attempts to develop the poorer rural regions after the wave of decolonization in the 1950s and 1960s: community development as a government-sponsored approach is mainly well known in the example of independent India. However, the popularity of community development with governments in developing countries was on the wane by the 1970s: it was considered to have had limited success and attention shifted to the search for immediate technical solutions to the problems of rural poverty (Gaik, 1981). The late 1970s onwards, as a reaction to the state-led approach to community development, that publications commenced to emerge whose focus was on encouraging peasant farmers and the poor to be the initiators of their own development-in this way the last would be put first (Chamber,1983).

With the end of the Cold War, the growth of 'neo-liberal' approaches to state welfare provision and the reduction in the capacity and resources of the state in many countries, 'collective self-help' has been announced as the way to address the needs of poor communities (De Berry,1999). International organizations and other national institutions have now come to see community development as a well-organized way of mobilizing labour and controlling resources as the state is rolled back. However, they emerge to want to take on this support of community organizations themselves, rather than leave engagement with the grassroots to the NGO sector, or newly emerging self-governance bodies. This can perhaps be seen as a response to the perceived failure of NGOs to solve problems of poverty in the developing world.

Community development in Pakistan has a long history; some aspects of community development can even be traced back to the colonial period, i.e. before partition. Significant are early efforts of the Christian Missions, which established rural reconstruction centers that motivated trained multi-purpose village workers. It also made health, educational and social welfare institutions in the targeted areas as part of their missionary work (Charles, 1958). 
By the end of the Second World War and the formation of Pakistan thereafter, development theorist and practitioners had already a rooting of thought on community development which emerged from such experiences. In the early days basically four ideas framed the direction of thought on community development policies in Pakistan:

- the concept of rural reconstruction, i.e. the holistic approach of total village development; this concept went together with the broader development philosophy of developing rural areas, which in the early 50th was not commonplace because at that time the term development was more commonly associated with the industrial sector;

- the concept of Government initiated/guided integrated community development that would bring together all sectoral line departments at the local level to approach the various development problems simultaneously;

- the concept of involving the communities and the civil society at large in rural development efforts in the form of localized participatory organizations; and,

- the concept of self-help and community co-operation, i.e. the notion of self-reliance at the local level (Jameel,1980).

Community development as an approach officially was introduced in 1951, when first UN advisor came in March 1952, analyzed the problems and needs suggested professional approach. Since 1951 till today various community development programs were implemented by government and non-government organizations (NGOs).The main aims of various community development programs were to bring to planned socio-economic change in the country. On the second of April 1953, sixty-five social workers trained in the first in-service Training Course, sponsored by the Government of Pakistan and United Nations Technical Administration (UNTAA), took the above Oath of Dedication at an impressive ceremony at Khalikdina Hall at Karachi presided over by the then Minister for Health, Labour and works, Dr. A.M Malik. This was a turning point in the history of community development in Pakistan as it give a new direction to community development and changed it from a charity oriented voluntary activity to a modern scientific profession (Shireen,2002).

The idea behind community development programs was not only to meet the basic needs of the people and also to provide effective means for their social education, but also to integrate them into cohesive communities. As Anwar (2008) stated that these programs emphasized on basic education, health, i.e. hygiene and sanitation, organized collective efforts, development of cottage industries, and community development through self-help, social welfare and relief measures. 


\section{Research Methodology}

In the methodological term, a population is the aggregate of all cases that confirm to some designated set of specification "people" and "residing in any area". Since the problem of the present study is community development programs for socioeconomic development in Pakistan, the study was conducted in three provinces (Sindh, Khyber Pakhtunkhwa and Balochistan) and Gilgit-Baltistan. Each province was selected as the unit of study. From Sindh and Balochistan province two UCs and from Khyber Pakhtunkhwa and Gilgit Baltistan one UC were selected as the universe from where structured questionnaires were executed for the purpose of data collection. These areas had been chosen where major community development programs have been implemented. Both qualitative and quantitative methods were used to collect general and focused data and conclusion. The purposive and convenience techniques of non-probability sampling method were applied. For this study the sample size of two hundred twenty-five (225) was determined for functional statistical manipulations. It was also decided to divide equally among fifteen NGOs, i.e. fifteen addresses each. SPSS was used for the analysis of the data.

The main objective of this study relates the roles and contributions of community development programs in Pakistan, the respondents were asked to recognize, the impacts of programs in the socio-economic development of their communities. Secondly, the respondents were asked to comments about community development programs contribution towards enhancing their living standard as well as their expectations from such programs. A conscious effort was made to recognize the impacts and contributions of community development programs in Pakistan.

\section{Results and Discussion}

First of all, the involvement of the native communities is vital to the success of community development programs. In the absence of community participation, the programs are plagued with the political and bureaucratic mess and corruption at every level. We cannot deny the contribution of community development programs in Pakistan and that they have a positive impact on individual's lives and up their socio-economic condition. The findings of study show that local community involvement in decision making process of community development programs is very low. The findings detail showed on Table No 1. 
Table: 1

Participation of respondents in the decision process

\begin{tabular}{|l|c|c|}
\hline Participation of Local communities & Frequency & Percentage \\
\hline Yes & 97 & $43.12 \%$ \\
\hline No & 128 & $56.88 \%$ \\
\hline Total No. of Respondents & $\mathbf{2 2 5}$ & $\mathbf{1 0 0 \%}$ \\
\hline
\end{tabular}

\section{Findings}

The study reveals that most of the respondents (56.88\%) haven't been involved in any decision making process of community development programs. The second highest respondents who were $43.12 \%$ said that they have been involved in decision making process of community development programs.

The community development programs were enforced to improve the socioeconomic condition and use the prevailing recourses in a better way. According to the study findings, the foremost programs satisfied to fulfil the expectations of people, but in some extent programs have failed to improve the living conditions. However, programs created some job opportunities for the influential individuals and created some positive impact on financial gain distribution within the urban areas. The findings detail showed on Table No 2.

Table: 2

How successful do you rate these community development programs

\begin{tabular}{|l|c|c|}
\hline Successful Rate & Frequency & Percentage \\
\hline Success & 46 & $20.44 \%$ \\
\hline Satisfaction & 91 & $40.45 \%$ \\
\hline Not satisfied & 88 & $39.11 \%$ \\
\hline Total No. of Respondents & $\mathbf{2 2 5}$ & $\mathbf{1 0 0 \%}$ \\
\hline
\end{tabular}

\section{Findings}

The table 2 indicates that majority of respondents, formed a percentage of $40.45 \%$ were satisfied with community development programs outcomes. The respondents who formed a percentage of $39.11 \%$ claimed non-satisfaction to the community development programs. Whereas only $20.44 \%$ respondents said that the programs are very successful at their communities.

The study showed that local culture and community heads have a great influence on community development programs and extreme favouritism and political manipulation as the both opponents tried their best to stain the development efforts initiated by their opponents. The lack of efficiency and low coverage of the 
existing community development programs make them unsatisfied. Poor people have very less participation and low exposure. The findings detail showed on Table no $3 \& 4$.

Table: 3

Local culture and community head influence on community development programs

\begin{tabular}{|l|c|c|}
\hline Culture and Community Head Influence & Frequency & Percentage \\
\hline Yes & 189 & $84 \%$ \\
\hline No & 36 & $16 \%$ \\
\hline Total No. of Respondents & $\mathbf{2 2 5}$ & $\mathbf{1 0 0 \%}$ \\
\hline
\end{tabular}

Findings: The table no 3 indicates that a majority of respondents $84 \%$ which is highest number of them think that local culture and community head have great influence on community development programs at their communities. The second highest and least number of respondents said that to some extent local culture and community head have influence on community development programs at their communities. They have formed a percentage of $16 \%$.

Table: 4

Challenges for effective local people participation in community development programs

\begin{tabular}{|l|c|c|}
\hline Challenges/ Limitations & Frequency & Percentage \\
\hline Political /key influencers interfere & 68 & $30.22 \%$ \\
\hline Lack of collective effort & 87 & $38.66 \%$ \\
\hline Lack of awareness & 70 & $31.11 \%$ \\
\hline Total No. of Respondents & $\mathbf{2 2 5}$ & $\mathbf{1 0 0 \%}$ \\
\hline
\end{tabular}

\section{Findings}

$38 \%$ had the view that lack of collective effort is the key challenge for local people participation in community development programs at their communities. The second highest number of respondents said that lack of awareness is a challenge for local people participation in community development programs. They have formed a percentage of $31.11 \%$. Whereas $30.22 \%$ of respondents who said that Political /key influencers interfere is a challenge for local people participation in community development programs at their communities.

It is obvious from the main findings of the study that contribution of NGOs towards the community development in general is very positive and appreciated but a lot of works are needed to be done by the growing number of NGOs in country, for the welfare of whole society. These they can do from side to side an 
effective mutual programs and strategies with an effective and efficient leadership structure. The findings detail showed on Table no 5.

Table: 5

How effective NGOs programs is improving local people lives

\begin{tabular}{|l|c|c|}
\hline NGOs Programs & Frequency & Percentage \\
\hline Effective & 116 & $51.55 \%$ \\
\hline Non-effective & 109 & $48.45 \%$ \\
\hline Total No. of Respondents & $\mathbf{2 2 5}$ & $\mathbf{1 0 0 \%}$ \\
\hline
\end{tabular}

\section{Findings}

The table no 5 indicates that highest number of respondents which had formed a percentage of $51.55 \%$ said that NGOs programs are improving local people lives at their communities. Whereas $48.45 \%$ of respondents said that NGOs programs are not improving local people lives at their communities.

Overall community development programs have very positive impacts on people lives throughout country. To be able to achieve community development programs objectives in Pakistan. It is very important to involve local communities in the process of development. The findings of study showed on table no 6.

Table: 6

Do you think the program have impacts on people lives

\begin{tabular}{|l|c|c|}
\hline Impacts on People Lives & Frequency & Percentage \\
\hline Yes & 128 & $56.88 \%$ \\
\hline No & 97 & $43.12 \%$ \\
\hline Total No. of Respondents & $\mathbf{2 2 5}$ & $\mathbf{1 0 0 \%}$ \\
\hline
\end{tabular}

\section{Findings}

The table no 6 indicates that highest number of respondents which had formed a percentage of $56.88 \%$ said that community development programs have very positive impacts on people lives at their communities. Whereas $43.12 \%$ of respondents said that community development programs don't have impacts on people lives at their communities.

Community development programs like Zakat, BISP, and Bait-ul-Mal, lack of targeting are the major problem. These programs do not have any transparent and reliable method of targeting the justified people, which refuses common and unsource able people from these programs. According to World Bank report (2007), $37 \%$ beneficiaries receiving rehabilitation grants were not poor. The report also provided evidence of misuse and nepotism in the Zakat delivery system. The 
selection of beneficiary's criteria was not clear; either corrupt was taken from the people or some supporters were involved in influencing to get Zakat.

\section{Recommendations}

Based on the research findings and observations, the researcher would like to make the following recommendations,

- This study also recommends that the government departments and NGOs should organize different kinds of programs to educate and makes awareness to the people about community development programs because a large number of the people seem not understand/awarded about the programs and importance of community development. They must get awareness on their requirement in participating in the process of developing their communities.

- Communication gap was found between Government/NGOs and communities. Therefore, it is recommended that Government and NGOs should build up its relations with communities in terms of community development programs.

- The departments/organizations have very good and strong relations with the key influencers of the targeted communalities. However, the relations with common people especially with needy people are very week. Therefore, it is recommended that government departments and NGOs should focus on these issues and also make sure the grassroots institution more strong in the targeted areas before heading over the programs to the local communities.

- There is a great need for research and training for NGO staffs. Equally of huge importance is the vital need for NGOs to look inner, in sourcing funds for its community development programs internally, rather than waiting for the external support of international donors alone.

- The study showed that the community development programs are mostly reliant on external donors. There is no appropriate system that tries have been made to develop project funds locally. Thus, it is recommended that the NGOs should use its potential to mobilize local supporters to raise project funds locally.

- Credit policies to promote farm investment and rural micro enterprises Policies to promote human capital to expand the capabilities of the poor Development of rural financial markets.

- Self-Help Group Approach to be strengthened as it is a proven method of empowerment of the poor. 


\section{References}

Alam, Anwer (2008). Community Development and Social Welfare. Peshawar, Pakistan: New Awan Printers.

Abbas, M. T. E. Lodhi, K. Mehmood \& S. Muhammad (2009). An Agricultural Extension Programs in Punjab. Pak. J. Life and Soc. Sci., vol.7:1, pp.1-10.

Aziz, S. (2009). Between Dreams and Realities: Some Milestones in Pakistan's History. Karachi, Pakistan Oxford University Press.

Charles R. Horton (1958). The Village Aid Program in Pakistan. Karachi, Pakistan: United States Information Services Pakistan.

Chaudhry, K.M. (2002). Community Infrastructure Services Program (CISP): HRD manual. Muzafarabad, Pakistan: Department of Local Government and Rural Development, Govt. of AJK.

Chambers, R. (1983). Rural Development: Putting the Last First. London, UK: Longman.

Dunham, Arthur. (1970). The New Community Organization. New York: Thomas Y. Crowell Company.

De Berry, J. (1999). Exploring the Concept of Community: Implications for NGO Management. LSE, UK: Centre for Voluntary Organization.

Daily Express Tribune (2015, April 15). World Bank projects: Pakistan's economic growth at $4.4 \%$. Karachi. Retrieved from the website: http://tribune.com.pk/story/870142/world-bank-projects-pakistanseconomic-growth-at-4-4/.

Ferrinho, H. (1980). Towards the Theory of Community Development. South Africa. Juta \& Comp. Ltd.

Gaik, V.R. (1981). Community Development in India. New Delhi, India: Allied Publishers Private Limited.

Hasan, Arif (2010). Participatory Development: The story of the Orangi Pilot Project-Research and Training Institute and the Urban Resource Center. Karachi, Pakistan: Oxford University Press.

Hillway, T. (1964). Introduction to Research. Boston, USA: Houghton Miffin. 
Ismail, Maimunah. (2001). Community Development: Distance Education Module: Institute for Distance Education. University Putra Malaysia, Kuala Lumpur.

Ife, J. (1999). Community Development: Creating Community Alternatives Vision, Analysis and Practice. Melbourne, Australia: Longman.

Jameel, Siddiqi (1980). A Review of Rural Development Programs. Islamabad, Pakistan: Government of Pakistan.

Khan, Shanza \& Sara Qutub (2010). The Benazir Income Support Program and the Zakat Program: A Political Economy Analysis of Gender. London, UK Overseas Development Institute.

Khan, S. \& Mahmood Hasan (1992). Rural Change in the Third World: Pakistan and the Aga Khan Rural Support Program. New York, USA: Greenwood Press, Print.

Lukkarinen, M. (2005). Community Development, Local Economic Development and the Social Economy. Community Development Journal, vol.40:4, pp.419-24.

Mukherji, B. (1961). Community Development in India. Bombay: Orient Longman.

NRSP. (2014). 20th Annual Progress Report. Islamabad, Pakistan: NRSP.

Pearce, J. (2000). Development, NGO and the Civil Society. Oxfam Publication Limited, United Kingdom.

Qureshi, Sarfraz (2001). An Overview of Government's Poverty Alleviation Policies and Programs. Islamabad, Pakistan: Pakistan Institute of Development Economics, Pakistan.

Rubin, H. J. \& Rubin, I. S. (1992). Community Organizing and Development. Boston, USA: Allyn \& Bacon.

Shireen, Rehmatullah (2002). Social Welfare in Pakistan. Karachi, Pakistan: Oxford University Press.

The Aga Khan Rural Support Program in Pakistan (1999). A World Bank Operations Evaluation Study. Washington, D.C., USA: World Bank. 
United Nation (1975). Popular Participation in Decision Making for Development. New York, USA; UNO Publications.

United Nations Development Programs (2014). Human Development Report. New York, USA: Oxford University Press.

Siraj Bashir is Teaching Assistant in the Department of Social Work, University of Karachi.

Dr. Nasreen Aslam Shah is Meritorious Professor \& Chairperson in the Department of Social Work and Director, Centre of Excellence for Women's Studies, University of Karachi. 